\title{
The translation of an antiapoptotic protein HIAP2 is regulated by an upstream open reading frame
}

\author{
D Warnakulasuriyarachchi ${ }^{1,2}$, NH Ungureanu ${ }^{1,2}$ and M Holčík ${ }^{\star, 1,2}$ \\ 1 Solange Gauthier Karsh Molecular Genetics Laboratory, Children's Hospital of \\ Eastern Ontario Research Institute, Canada \\ ${ }^{2}$ Department of Pediatrics, University of Ottawa, 401 Smyth Road, Ottawa, \\ Canada ONK1H 8L1 \\ * Corresponding author: M Holčík; Molecular Genetics Laboratory, Childrens' \\ Hospital of Eastern Ontario Research Institute, Room R310, 401 Smyth Road, \\ Ottawa, ON, Canada K1H 8L1. Tel: +1 (613) 738 3207; \\ Fax: +1 (613) 738 4833; E-mail: martin@mgcheo.med.uottawa.ca
}

Received 9.12.02; revised 27.2.03; accepted 28.2.03

Edited by $\mathrm{G}$ Salvesen

\begin{abstract}
HIAP2 is a multifunctional protein that is critically involved in the regulation of cell survival and apoptosis. Here, we show that HIAP2 $5^{\prime}$ untranslated region functions as a strong inhibitor of translation. Sequence analysis of human, mouse and rat sequences revealed that there exists a short open reading frame (ORF) that is located just upstream of the HIAP2 coding sequence. The translation of this uORF severely inhibited translation of the downstream reporter gene in vivo but not in vitro. Point mutation that destroys the CUG initiating codon of uORF markedly enhanced translation of the reporter gene without affecting the mRNA levels. Our results identify a novel translational regulatory mechanism that controls the expression of HIAP2 and point to the importance of tight regulation of antiapoptotic gene expression.

Cell Death and Differentiation (2003) 10, 899-904. doi:10.1038/ sj.cdd. 4401256
\end{abstract}

Keywords: translational control; uORF; IRES; IAP; caspase; apoptosis

\begin{abstract}
Abbreviations: UTR, untranslated region; IAP, inhibitor of apoptosis protein; TNF, tumour necrosis factor; BIR, baculoviral IAP repeat; RING, really interesting new gene; IRES, internal ribosome entry site; CAT, chloramphenicol acetyltransferase; $\beta$ gal, $\beta$-galactosidase; ELISA, enzyme-linked immunosorbent assay; RPA, ribonuclease protection assay; ONPG, o-nitrophenyl- $\beta$-D-galactopyranoside.
\end{abstract}

\section{Introduction}

Apoptosis is a genetically programmed process that is unique to multicellular organisms. Apoptosis has likely evolved specifically to regulate cellular homeostasis by removing damaged or redundant cells that could otherwise jeopardize survival of the whole organism. Indeed, dysregulated apoptosis has been implicated in varied disorders ranging from cancer to autoimmunity to neurodegeneration. The control and therapeutic regulation of apoptosis has therefore emerged as a key pharmacological target ${ }^{1}$ underlying the importance to study the mechanisms of apoptosis. The inhibitor of apoptosis (IAP) family of proteins are considered to be the key regulators of apoptosis by virtue of their ability to directly bind and inhibit distinct caspases. ${ }^{2}$ Although the Xlinked inhibitor of apoptosis, XIAP, is the most potent inhibitor of both the initiator and effector caspases, other members of the IAP family are thought to play important roles in a subset of apoptotic conditions. ${ }^{3,4}$

HIAP2 (GenBank XM040717; also known as c-IAP1, MIHB, BIRC2) was initially identified through the interaction with the tumour necrosis factor (TNF)-receptor complex proteins TRAF1 and TRAF2. ${ }^{5}$ HIAP2 is a multifunctional protein with at least three distinct functions. First, HIAP2 suppresses apoptosis induced by various triggers by directly binding to and inhibiting caspase-3 and $-7 .{ }^{6}$ Second, HIAP2 interacts with TRAFs and regulates the signaling through the TNF receptor. ${ }^{5}$ Third, HIAP2 possesses an ubiquitin E3 ligase activity. ${ }^{7}$ Interestingly, while the caspase inhibition and interaction with TRAFs are mediated by the $\mathrm{N}$-terminal baculoviral IAP repeat (BIR) domains and is generally considered antiapoptotic, the E3 ligase activity is exerted by the C-terminal RING zinc domain and sensitizes cells to apoptosis by directing ubiquitylation and removal of TRAF2 following the activation of TNF receptor. ${ }^{7}$ In addition, a proapoptotic form of HIAP2, that is, produced by cleavage of HIAP2 during apoptosis was also described. ${ }^{8}$ This variant of HIAP2 lacks the BIR domains and contains only the Cterminal RING zinc domain further supporting the notion that HIAP2 can exert both prosurvival and prodeath signals through its distinct domains.

Given the critical role the IAPs play in the regulation of apoptosis, it is not surprising that their expression is tightly controlled at different levels of gene expression. For example, HIAP1 is regulated transcriptionally by the NF-kB regulatory network, ${ }^{9}$ while the expression of XIAP was shown to be regulated translationally via a potent internal ribosome entry site (IRES) element. ${ }^{10}$ Not much is known about the regulation of HIAP2 expression. HIAP2 is expressed in all tissues examined but, except in the brain, at levels substantially lower than that of HIAP1. ${ }^{11}$ Interestingly, the amplification of hiap2 locus was reported in esophageal squamous cell carcinomas. ${ }^{12}$ Significantly, HIAP2 protein levels were increased in the primary tumours and the cells established from these tumours were resistant to apoptosis induced by a variety of chemotherapeutic agents. ${ }^{12,13}$ Examination of the $\mathrm{NCl}$ panel of 60 tumour-derived cell lines also revealed that higher levels of HIAP2 protein were associated with resistance to several anticancer drugs ${ }^{14}$ Furthermore, this study also showed that the hiap2 mRNA levels did not correlate with protein levels in tumour cells suggesting a posttranscriptional control of expression. 
In this work, we have investigated the mechanism of regulation of HIAP2 expression. We demonstrate that although the HIAP2 mRNA has very long $5^{\prime}$ untranslated region (UTR), it is not translated by an IRES mechanism. In contrast, there exists a small open reading frame (ORF) in the HIAP2 $5^{\prime}$ UTR that is located just upstream of the HIAP2 coding reading frame. The translation of this UORF inhibits translation of HIAP2 in vivo. Our results demonstrate an existence of distinct mechanisms that control the expression of genes critically involved in the regulation of apoptosis.

\section{Results and Discussion}

\section{Translation of HIAP2 is initiated at the downstream AUG}

The IAP HIAP2 contains an unusually long $5^{\prime}$ UTR. ${ }^{11}$ Unlike its mouse homologue, the $5^{\prime}$ UTR of human HIAP2 is also bisected by a short intron. ${ }^{11}$ The inspection of the $1.2 \mathrm{~kb}$ HIAP2 $5^{\prime}$ UTR sequence which is available in GenBank (accession numbers NM001166 and XM040717) disclosed that there exists $23 \mathrm{AUG}$ codons and two upstream putative ORFs that precede the reported initiation AUG start site. Furthermore, in the human HIAP2 coding region, there exists a downstream AUG 1222 that is located 63 nucleotides (nt) after the initiation site (AUG 1159). The comparison of mouse, ${ }^{15}$ rat $^{16}$ and human sequences revealed, however, that the initiation AUG codon that is assigned to HIAP2 gene (AUG 1159) is not present in the rat sequence. In contrast, the downstream AUG is conserved in all the three species (Figure 1a). It is therefore possible that it is the second AUG, and not the first $A \cup G$, which is used as the initiation site to produce the HIAP2 protein. The difference between these two HIAP2 proteins is 21 amino acids and will likely have no impact on the function of the HIAP2 gene. However, in order to consider the regulatory role of the $5^{\prime}$ UTR, the knowledge of the initiation site is critical. We have therefore constructed a plasmid containing 149 nt fragment of HIAP2 $5^{\prime}$ UTR that includes both $A U G$ codons cloned in frame with the chloramphenical acetyltransferase (CAT) reporter gene (plasmid HIAP2 (1073-1222)CAT; Figure 1b). Coupled in vitro transcription and translation of this plasmid identified two CAT products, 26 and $29 \mathrm{kDa}$, respectively (Figure 1c). The size difference between these products is very similar to the expected difference if both HIAP2 AUG codons were used (2.4 kDa), suggesting that both initiation codons are in fact utilized. To further confirm that the larger, $29 \mathrm{kDa}$ band is because of the presence of the first initiation codon (AUG 1159), site-directed mutagenesis was used to introduce a single point mutation (AUG/AUA) at this site. Importantly, this mutation completely abolished the appearance of the larger band confirming that the AUG 1159 gives rise to the larger CAT product. Interestingly, the relative intensity of both the bands is significantly different with the smaller band being synthesized about 15-fold more efficiently than the larger band. This suggests that the downstream AUG 1222 that produces a smaller product is used more frequently than the upstream AUG. Our results thus suggest that although there exist two inframe AUG codons within the first $63 \mathrm{nt}$ of the HIAP2 coding region, it is the second, downstream AUG that is used to a

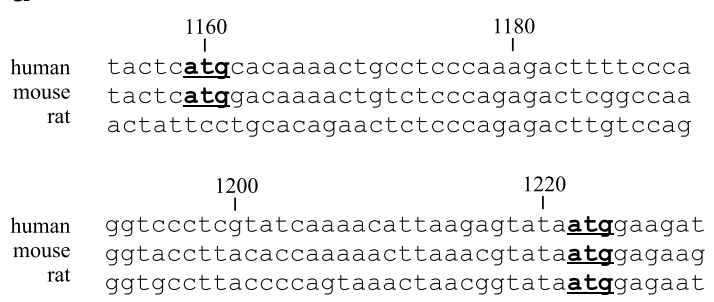

b

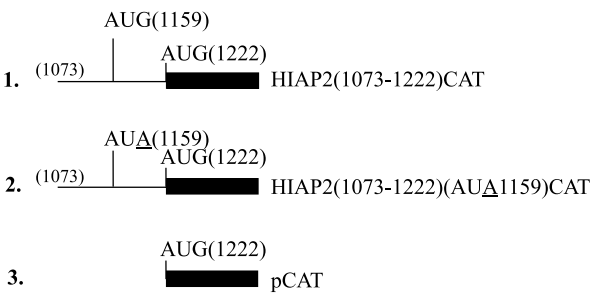

C

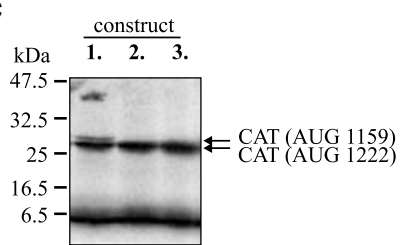

d

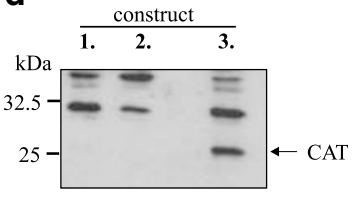

Figure 1 Translation of HIAP2 is initiated at AUG1222. (a) Sequence alignment of the segment of human, mouse and rat HIAP2 coding region. Two inframe AUG codons are underlined. (b) Schematic diagram of the reporter plasmids. Black box represents the CAT reporter gene. Numbers in brackets indicate nucleotide coordinates on HIAP2 mRNA. (c) Reporter plasmids shown in (b) were in vitro translated as described in Material and Methods and separated on $12.5 \%$ SDS-PAGE. Arrows indicate the position of CAT products. Identity of plasmid constructs is shown above each lane and corresponds to the labeling in (b). (d) Reporter plasmids shown in (b). were transiently transfected into 293T cells and the levels of CAT were determined by Western blot analysis $24 \mathrm{~h}$ posttransfection. The arrow indicates the position of the CAT product. Identity of plasmid constructs is shown above each lane and corresponds to the labeling in (b)

produce HIAP2 protein. For further experiments, therefore, we considered the sequence $5^{\prime}$ to the AUG (1222) to be an UTR.

To confirm the in vitro data in cell culture, the plasmid HIAP2(1073-1222)CAT was transiently transfected into 293T cells and the size of the CAT product was inspected by Western blot. Surprisingly, however, we could not detect any CAT products from this construct although the control CAT plasmid produced a protein band of the expected size $26 \mathrm{kDa}$ (Figure 1d). These data suggest that the $5^{\prime}$ UTR of HIAP2 is refractory to translation in vivo but not in vitro.

\section{HIAP2 5' UTR does not contain IRES element}

The $5^{\prime}$ UTR of HIAP2 is unusually long and could be potentially refractory to the ribosomal scanning, which could explain our observation that the HIAP2 $5^{\prime}$ UTR severely reduces translation of the reporter gene. Since a related antiapoptotic gene, XIAP, also contains an unusually long $5^{\prime}$ UTR and has been shown to contain a potent IRES element, ${ }^{10}$ we wished to test if HIAP2 5' UTR also contains an IRES. The 
1222 nt $5^{\prime}$ UTR region of HIAP2 was cloned into the bicistronic reporter vector $\mathrm{p} \beta \mathrm{gal} / \mathrm{CAT}$ and the activity of both the reporter genes was determined in transiently transfected 293T cells. As Figure 2 indicates, the $5^{\prime}$ UTR of HIAP2 was unable to direct translation of the downstream reporter gene above that of the vector with antisense HIAP2 5' UTR. For comparison, we used the IRES element of XIAP that was able to mediate translation of CAT gene at 150-fold higher levels than the control plasmid (antisense XIAP 5' UTR). Therefore, our results indicate that HIAP2 does not contain a functional IRES element.

\section{Translation of downstream gene is inhibited by HIAP2 5' UTR}

Given the fact that the $149 \mathrm{nt}$ fragment of HIAP2 $5^{\prime}$ UTR prevented translation of the CAT reporter gene (Figure 1d) and we could not detect IRES activity in the UTR, we wished to understand how is the HIAP2 coding region is translated. We have therefore constructed a series of monocistronic plasmids in which the reporter gene, CAT, is preceded by progressive deletions of the HIAP2 UTR (Figure 3a). The monocistronic plasmids were cotransfected along with $\mathrm{pCMV} \beta$ gal into 293T cells and the levels of $\beta \mathrm{gal}$ and CAT were determined. We observed that all constructs significantly reduced translation of the CAT gene when compared to the construct without the UTR (Figure $3 b$ ). This observation was rather surprising since the smallest $5^{\prime}$ UTR construct HIAP2(1142-1222)CAT contains only $80 \mathrm{nt}$ of the UTR sequence. In contrast, insertion of the $1.1 \mathrm{~kb} 5^{\prime}$ UTR region of XIAP had no effect on CAT translation. Our data therefore suggest that HIAP2 $5^{\prime}$ UTR sequence imposes a significant constraint on the translation of the downstream ORF. Alternatively, the lack of translation could be because of the instability of the mRNA containing the HIAP2 $5^{\prime}$ UTR. We have therefore tested the expression levels of CAT mRNA produced by various constructs by RNase protection assay and found that the presence of HIAP2 $5^{\prime}$ UTR did not affect mRNA levels (data not shown).

We next considered a possibility that the inhibition of translation exerted by HIAP2 $5^{\prime}$ UTR is only specific to $293 T$ cells. We cotransfected various cells (Hela, NIH 3T3, PANC1 and SF268) with the HIAP2(1-1222)CAT and HIAP2(10731222)CAT plasmids and assayed the translation efficiency of CAT in each cell line (Figure 3d). The $5^{\prime}$ UTR of HIAP2 inhibited translation of CAT reporter gene in every cell line tested, indicating the translational inhibition is shared by various cell types, both human and murine.

\section{Translation of HIAP2 is controlled by an upstream ORF}

Close inspection of the HIAP2 $5^{\prime}$ UTR revealed that there exists a short putative ORF located just upstream of the HIAP2 coding sequence (Figure 4a). This putative ORF would be initiated at CUG (position 1147) and be terminated at position 1213, just 8 nt upstream of the HIAP2 AUG (1222). This upstream ORF is positioned in -1 frame relative to the HIAP2 ORF and would produce a 22 amino-acid long polypeptide. We hypothesized that the translation of this uORF could prevent translation of the HIAP2 gene. To confirm this hypothesis, the CUG codon was mutated in plasmid HIAP2(1073-1222)CAT and the effect of this mutation of the translation of downstream CAT gene was tested in the 293T cells (Figure $4 \mathrm{~b}$ ). We observed that this single point mutation (CUG $\rightarrow$ CUA) dramatically enhanced translation of the reporter gene ( $\sim 25$-fold). In contrast, this mutation had no effect on the levels of CAT mRNA suggesting that, indeed, the translation of the UORF interferes with the HIAP2 translation (data not shown). To further confirm this hypothesis, we constructed a reporter plasmid HIAP2(UORF)CAT in which the CAT gene (without the initiator AUG) is cloned in frame with the UORF to produce a fusion protein (Figure 4c). We observed significant levels of CAT produced from this construct suggesting that indeed the uORF is translated in 293T cells. Furthermore, the mutation of the CUG codon abolished translation of the CAT gene confirming that the initiation occurs at this site (Figure 4c). When we used the HIAP2(UORF)CAT construct in the in vitro translation system, we were unable to detect any product (Figure $4 d$ ). This result corroborates our previous observation that the HIAP2 $5^{\prime}$ UTR exerts an inhibitory effect on translation in vivo but not in vitro

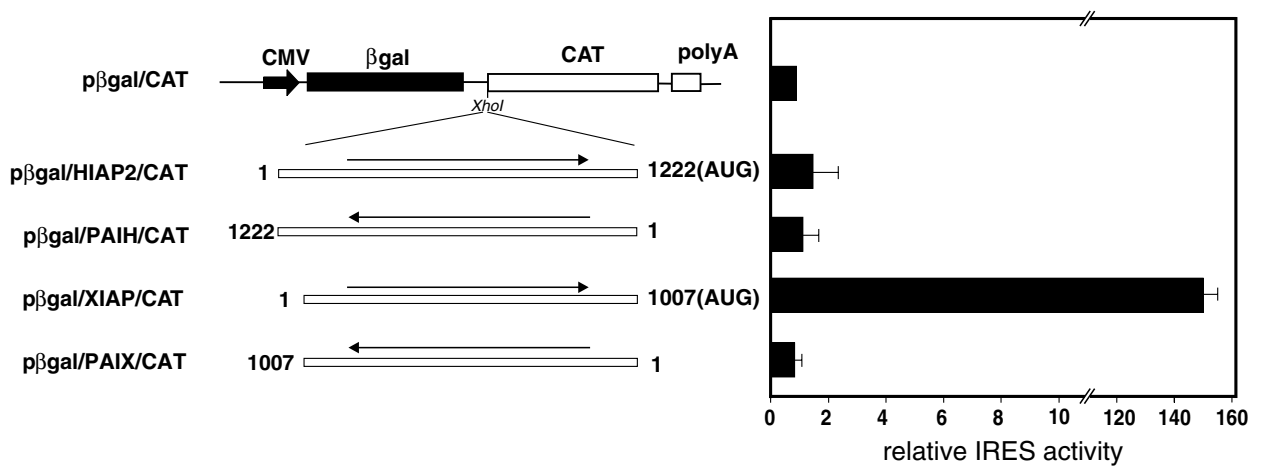

Figure 2 HIAP2 $5^{\prime}$ UTR does not contain an IRES element. DNA segments corresponding to the indicated regions of the human HIAP2 or XIAP $5^{\prime}$ UTRs were inserted into the Xhol site in the linker region of the bicistronic plasmid $\mathrm{p} \beta \mathrm{gal} / \mathrm{CAT}$ in the indicated directions. The ability of the UTR to facilitate internal initiation was assessed in transiently transfected 293T cells. Relative IRES activity was determined $24 \mathrm{~h}$ post-transfection as a ratio of CAT/ $\beta$ gal. The activity of the empty vector $\mathrm{p} \beta \mathrm{gal} / \mathrm{CAT}$ was set as 1 . The bars represent the average \pm S.D. of three independent transfections performed in triplicates 
a

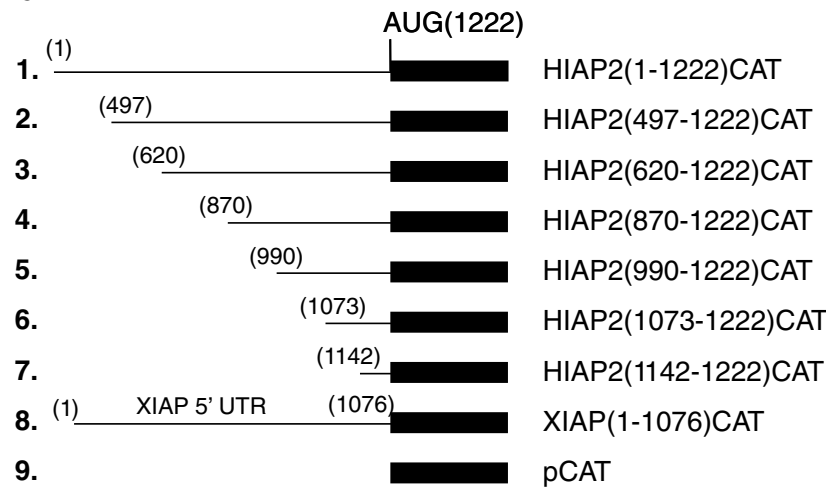

b

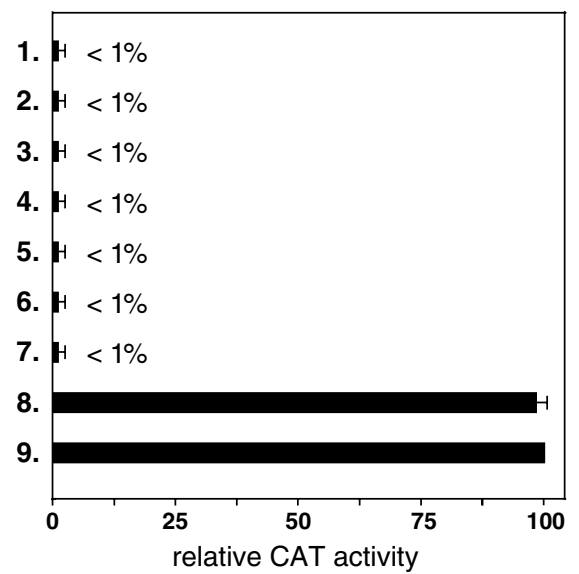

C

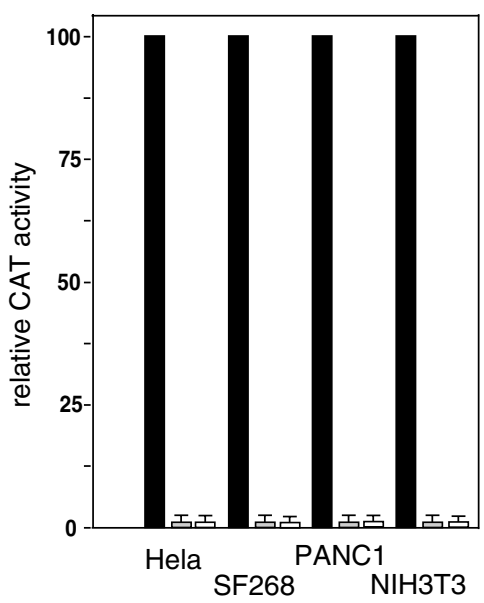

Figure 3 HIAP2 5' UTR inhibits translation of the reporter gene in vivo. (a) DNA segments corresponding to the indicated regions of the human HIAP2 $5^{\prime}$ UTR were inserted in front of the CAT reporter gene (shown as a black box). Numbers in brackets indicate the nucleotide coordinates on the HIAP2 mRNA. (b) 293T cells were transiently cotransfected with the plasmids shown in (a). and plasmid pCMV $\beta$ gal, and the CAT and $\beta$ gal activities were determined $24 \mathrm{~h}$ posttransfection. The relative CAT activity was determined as a ratio of CAT/ $\beta$ gal. The activity of the PCAT plasmid was set as 100 . The bars represent the average \pm S.D. of three independent cotransfections performed in triplicate. (c) Four cell lines (indicated below the $x$-axis) were cotransfected with plasmid HIAP2(1-1222)CAT (white bars), HIAP2(1073-1222)CAT (gray bars) or pCAT (black bars) and $\mathrm{pCMV} \beta$ gal and the relative translational efficiency was determined as in (b)
(Figure 1c and d) suggesting that the rabbit reticulocyte lysate translation system does not support initiation at this CUG codon and could be used in future experiments to identify proteins involved in the regulation of HIAP2 translation.

While the presence of upstream ORFs is relatively rare in the eukaryotic mRNAs, it is much more common in the mRNA of genes involved in the regulation of cell growth and differentiation. ${ }^{17}$ It is thought that one role of uORFs is the precise control of the expression of these genes. Given the role HIAP2 plays in the control of apoptosis, a requirement for tight control may be necessary. Indeed, other members of the IAP family of genes are tightly controlled either transcriptionally (e.g. $\mathrm{HIAP}^{9}{ }^{9}$ ) or translationally (e.g. XIAP ${ }^{10}$ ). Here, we demonstrated that unlike XIAP, the translation of HIAP2 is not mediated via IRES. Instead, an UORF in the HIAP2 $5^{\prime}$ UTR significantly reduces translation of the HIAP2 gene. In this respect, our data parallel the observation that HIAP2 is expressed at only low levels in normal tissues. ${ }^{11}$ The translation of HIAP2 UORF is initiated at CUG codon, which is not an optimal initiation codon. However, there exists examples of other mRNAs in which translation is initiated at CUG codon, such as $c-m y c$ oncogene ${ }^{18}$ or the fibroblast growth factor FGF2. ${ }^{19}$

Given the partial overlap between XIAP and HIAP2 activity with respect to the caspase inhibition, the different modes of the regulation of XIAP and HIAP2 expression point to a possible involvement of these IAPs in distinct stress responses. We have shown previously that the expression of XIAP is increased following serum starvation, anoxia or lowdose $\gamma$ irradiation. ${ }^{10,20,21}$ In contrast, we did not observe any changes in the HIAP2 expression following serum starvation, UV irradiation, anoxia or treatment with etoposide (data not shown). In addition, treatment of cells with TNF $\alpha$, which was shown to induce expression of HIAP $1^{9}$ had no effect on the translation of HIAP2 reporter constructs in 293T cells or the levels of HIAP2 endogenous protein in various cell lines (data not shown). These results suggest that distinct regulatory mechanisms could be involved in the selective upregulation of specific antiapoptotic proteins in response to a particular stress. In this context, it is noteworthy that another antiapoptotic gene, Bcl2, has also been shown to be regulated translationally by an uORF located in its $5^{\prime}$ UTR. $^{22}$ Significantly, HIAP2 and Bcl2 inhibit apoptosis by two different mechanisms. ${ }^{4}$ At present, we do not know what cellular mechanism and/or physiological stress will lead to the translational upregulation of HIAP2. Neither was the mechanism of regulation of $\mathrm{Bcl} 2$ by its $\mathrm{UORF}$ described. It is tempting to speculate, however, that transitory apoptotic conditions may trigger transient increase in the levels of HIAP2 and BCL2 by a mechanism that involves translational regulation through their respective uORFs.

\section{Materials and Methods}

\section{Cell culture and reagents}

Human embryonic kidney (293T), human pancreatic carcinoma cells (PANC1), human cervical carcinoma cells (Hela), mouse embryonic fibroblast cells (NIH 3T3) and human glioma (SF268) were cultured in standard conditions in Dulbecco's Modified Eagle's Medium supplemented 
a

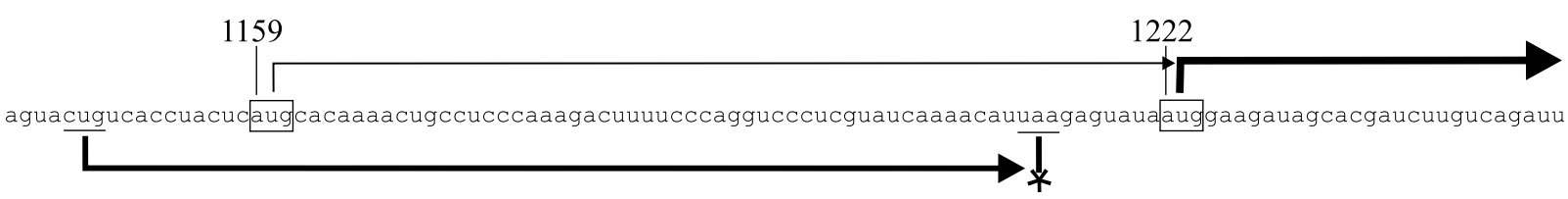

b

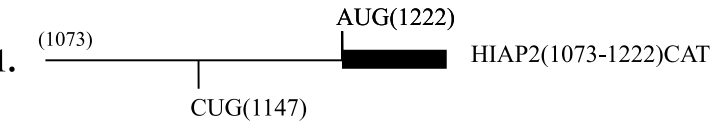

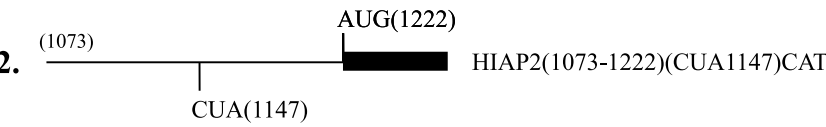

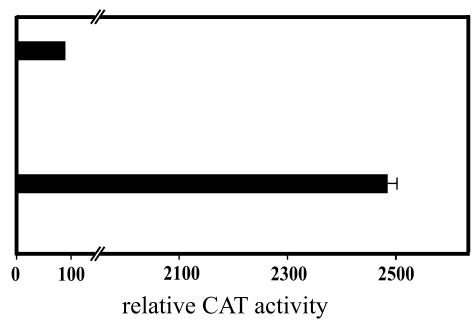

C
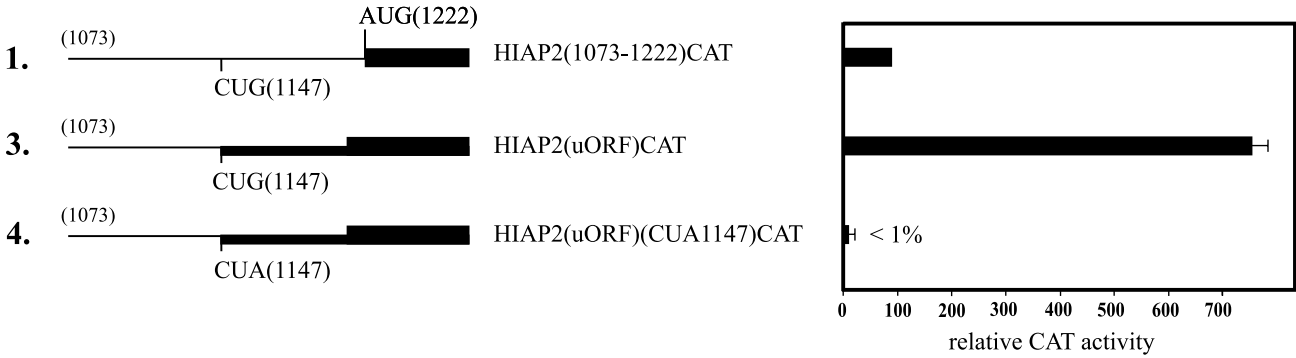

d

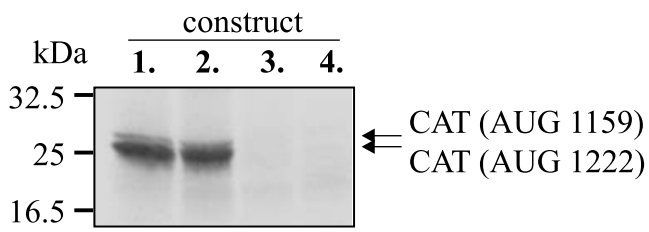

Figure 4 Upstream ORF regulates translation of HIAP2. (a) Nucleotide sequence of the HIAP2 $5^{\prime}$ UTR. The two AUG start sites of HIAP2 and the CUG and UAA delineating the UORF are indicated. The nucleotide coordinates are shown above the sequence. The thickness of arrows indicates the relative levels of translation from the indicated start site. $(\mathbf{b}, \mathbf{c})$ 293T cells were transiently cotransfected with the indicated plasmids (shown on the left) and pCMV $\beta$ gal, and the CAT and $\beta$ gal activities were determined $24 \mathrm{~h}$ post-transfection. The relative CAT activity was determined as a ratio of CAT/ $\beta$ gal. The activity of the HIAP2(1073-1222)CAT plasmid was set as 100. The bars represent the average \pm S.D. of three independent cotransfections performed in triplicate. (d) The reporter plasmids shown in $(\mathbf{b}, \mathbf{c})$. were in vitro translated as described in Material and Methods and separated on 12.5\% SDS-PAGE. Arrows indicate the position of CAT products. Identity of plasmid constructs is shown above each lane and corresponds to the labeling in $(\mathbf{b}, \mathbf{c})$.

with $10 \%$ fetal calf serum, glutamine and antibiotics as described previously. ${ }^{21}$ Transient DNA transfections were conducted using Lipofectamine Plus reagent (Invitrogen) with the protocol provided by the manufacturer. The bicistronic vector $\mathrm{p} \beta \mathrm{gal} / \mathrm{CAT}$, plasmid $\mathrm{p} \beta \mathrm{gal} / \mathrm{hUTR} /$ CAT containing the human XIAP IRES element and plasmids pCMV $\beta$ gal and PCAT expressing $\beta$-galactosidase and chloramphenicol acetyltransferase, respectively, were described previously. ${ }^{10}$ In all plasmids, the expression is directed from a CMV promoter. The fragments of HIAP2 $5^{\prime}$ UTR were RT-PCR amplified from total RNA isolated from Jurkat cells, TOPO TA subcloned (Invitrogen) and inserted into the linker region of the bicistronic vector $\mathrm{p} \beta \mathrm{gal} / \mathrm{CAT}$. Monocistronic plasmids were constructed by deleting the $\beta$ gal gene from the bicistronic constructs. Plasmids with mutated HIAP2 $5^{\prime}$ UTR were constructed by site-directed mutagenesis (QuickChange XL Mutagenesis Kit, Stratagene). The correct sequence and orientation of all constructs were confirmed by sequencing.

For the cellular stress experiments, 293T cells were cotransfected with $\mathrm{p} \beta$ gal and pCAT, HIAP2(1-1222)CAT or HIAP2(1073-1222)CAT plasmids as described above. At $24 \mathrm{~h}$ after transfection, the cells were exposed to the following stresses: anoxia $\left(90 \% \mathrm{~N}_{2}, 5 \% \mathrm{H}_{2}, 5 \% \mathrm{CO}_{2}\right.$ in
MACS-VA500 microaerophilic workstation; 24 and $48 \mathrm{~h}$ ), etoposide $(200 \mu \mathrm{M} ; 24$ and $48 \mathrm{~h})$, serum deprivation (24 and $48 \mathrm{~h})$, UV irradiation $\left(50 \mathrm{~J} / \mathrm{m}^{2}\right)$ and TNF $\alpha(20 \mathrm{ng} / \mathrm{ml}$ for $6 \mathrm{~h})$ for indicated times and then collected for analysis as described below. In case of UV and TNF $\alpha$ treatments, the cells were collected for analysis $24 \mathrm{~h}$ following exposure.

\section{Western blot analysis}

Cells were harvested in ice-cold PBS, lysed in RIPA buffer (1\% NP-40/1\% sodium deoxycholate/0.1\% SDS/0.15 M NaCl/0.01 M sodium phosphate, $\mathrm{pH} 7.2 / 2 \mathrm{mM}$ EDTA/0.1 mM PMSF) for $30 \mathrm{~min}$ at $4^{\circ} \mathrm{C}$ followed by centrifugation at $14000 \times g$ for $10 \mathrm{~min}$. Protein concentration was assayed by Protein Assay Kit (Bradford Assay; Bio-Rad Laboratories) and equal amounts of protein samples were separated by $10 \%$ SDSPAGE. Samples were analyzed by Western blotting using rabbit polyclonal anti-CAT (Sigma) or anti-HIAP2 (ÆEgera) antibodies at 1:10000 dilution followed by secondary antibody (horseradish peroxidase-conjugated goat anti-rabbit IgG; Amersham). Antibody complexes were detected using the ECL Plus system (Amersham). 


\section{$\beta$-Galactosidase and CAT analysis}

Transiently transfected cells were harvested $24 \mathrm{~h}$ post-transfection in the CAT ELISA kit lysis buffer (Roche) and cell extracts were prepared using the protocol provided by the manufacturer. $\beta$-Galactosidase enzymatic activity in cell extracts was determined by the spectrophotometric assay using o-nitrophenyl- $\beta$-D-galactopyranoside (ONPG), ${ }^{23}$ and the CAT levels were determined using the CAT ELISA kit (Roche) and the protocol provided by the manufacturer.

\section{In vitro transcription and translation}

Coupled in vitro transcription and translations (TnT Quick Coupled Transcription/Translation System, Promega) were performed under the conditions recommended by the manufacturer. Each reaction was programmed with $1 \mu \mathrm{g}$ of purified plasmid DNA of the monocistronic plasmids. In vitro translated proteins were labeled with L-[ $\left[{ }^{35} \mathrm{~S}\right]-$ methionine (Amersham). Reactions were incubated at $30^{\circ} \mathrm{C}$ for $90 \mathrm{~min}$ and analyzed on $12.5 \%$ SDS-PAGE. The intensities of the CAT band were determined on a BioRad Model GS-670 Imaging Densitometer.

\section{Ribonuclease protection assay}

Total RNA was isolated from transiently transfected cells with the Trizol reagent (Invitrogen) and treated with $1 \mathrm{U}$ of DNAse I. The ${ }^{32} \mathrm{P}$ labeled antisense RNA probes spanning 149 nt of the HIAP2 $5^{\prime}$ UTR (coordinates 1073-1222) or human GAPDH (Pharmingen) were synthesized using the MaxiScript T7 transcription kit (Ambion) and gel purified. RPA analysis was performed using the Ribonuclease protection assay (RPA) III kit (Ambion) and the protocol provided by the manufacturer. Briefly, $10 \mu \mathrm{g}$ of total RNA was hybridized overnight at $42^{\circ} \mathrm{C}$ with $5 \times 10^{4} \mathrm{cpm}$ of high specific activity probe and then digested with RNase A/RNase T1 mix. The digested samples were ethanol precipitated and separated on a denaturing polyacrylamide gel. The protected fragments were visualized by detection to X-ray film and quantified on a BioRad Model GS-670 Imaging Densitometer.

\section{Acknowledgements}

We thank the members of our laboratory for stimulating discussions, Jaime Blais for the help with the MACS-VA500 microaerophilic workstation and the University of California San Francisco/Neurosurgery Tissue Bank for the SF-268 cell line. This work was supported by the operating grant from the Canadian Institutes of Health Research (\# 43984). MH is a CIHR New Investigator.

\section{References}

1. Reed JC. (1999) Dysregulation of apoptosis in cancer. J. Clin. Oncol. 17: 2941

2. Holcik M, Gibson H and Korneluk RG. (2001) XIAP: apoptotic brake and promising therapeutic target. Apoptosis 6: 253-261

3. Holcik M and Korneluk RG. (2001) XIAP, the guardian angel. Nat. Rev. Mol. Cell. Biol. 2: 550-556
4. Salvesen GS and Duckett CS. (2002) Apoptosis: IAP proteins: blocking the road to death's door. Nat. Rev. Mol. Cell Biol. 3: 401-410

5. Rothe M, Pan MG, Henzel WJ, Ayres TM and Goeddel DV. (1995) The TNFR2TRAF signaling complex contains two novel proteins related to baculoviral inhibitor of apoptosis proteins. Cell 83: 1243-1252

6. Ekert PG, Silke J and Vaux DL. (1999) Caspase inhibitors. Cell Death Differ. 6: 1081-1086

7. Li X, Yang Y and Ashwell JD. (2002) TNF-RII and c-IAP1 mediate ubiquitination and degradation of TRAF2. Nature 416: 345-347

8. Clem RJ, Sheu TT, Richter BW, He WW, Thornberry NA, Duckett CS and Hardwick JM. (2001) C-IAP1 is cleaved by caspases to produce a proapoptotic C-terminal fragment. J. Biol. Chem. 276: 7602-7608

9. Chu ZL, McKinsey TA, Liu L, Gentry JJ, Malim MH and Ballard DW. (1997) Suppression of tumor necrosis factor-induced cell death by inhibitor of apoptosis c-IAP2 is under NF-kappaB control. Proc. Natl. Acad. Sci. USA 94: 10057-10062

10. Holcik M, Lefebvre CA, Yeh C, Chow T and Korneluk RG. (1999) A new internal-ribosome-entry-site motif potentiates XIAP-mediated cytoprotection. Nat Cell Biol 1: 190-192

11. Young SS, Liston P, Xuan JY, McRoberts C, Lefebvre CA and Korneluk RG. (1999) Genomic organization and physical map of the human inhibitors of apoptosis: HIAP1 and HIAP2. Mamm. Genome. 10: 44-48

12. Imoto I, Yang ZQ, Pimkhaokham A, Tsuda $H$, Shimada $Y$, Imamura M, Ohki $M$ and Inazawa J. (2001) Identification of clAP1 as a candidate target gene within an amplicon at 11q22 in esophageal squamous cell carcinomas. Cancer Res. 61: 6629-6634

13. Imoto I, Tsuda H, Hirasawa A, Miura M, Sakamoto M, Hirohashi S and Inazawa J. (2002) Expression of CIAP1, a target for 11q22 amplification, correlates with resistance of cervical cancers to radiotherapy. Cancer Res. 62: 4860-4866

14. Tamm I, Kornblau SM, Segall H, Krajewski S, Welsh K, Kitada S, Scudiero DA, Tudor G, Qui YH, Monks A, Andreeff M and Reed JC. (2000) Expression and prognostic significance of IAP-family genes in human cancers and myeloid leukemias. Clin. Cancer Res. 6: 1796-1803

15. Liston P, Lefebvre C, Fong WG, Xuan JY and Korneluk RG. (1997) Genomic characterization of the mouse inhibitor of apoptosis protein-1 and 2 genes. Genomics 46: 495-503

16. Holcik M, Lefebvre CA, Hicks K and Korneluk RG. (2002) Cloning and characterization of the rat homologues of the inhibitor of apoptosis protein 1,2 , and 3 genes. BMC Genomics 3: 5-10

17. Geballe AP. (1996) Translational control mediated by upstream AUG codons. In Translational Control, Hershey JWB, Mathews MB, Sonenberg N, eds (Cold Spring Harbor: Cold Spring Harbor Press) pp. 173-197

18. Nanbru C, Lafon I, Audigier S, Gensac MC, Vagner S, Huez G and Prats AC. (1997) Alternative translation of the proto-oncogene c-myc by an internal ribosome entry site. J. Biol. Chem. 272: 32061-32066

19. Vagner S, Gensac MC, Maret A, Bayard F, Amalric F, Prats H and Prats AC. (1995) Alternative translation of human fibroblast growth factor 2 mRNA occurs by internal entry of ribosomes. Mol. Cell. Biol. 15: 35-44

20. Nevins TA, Harder ZM, Korneluk RG and Holcik M. (2003) Distinct regulation of internal ribosome entry site-mediated translation following cellular stress is mediated by apoptotic fragments of elF4G translation initiation factor family members elF4GI, p97/DAP5/NAT1. J. Biol. Chem. 278: 3572-3579

21. Holcik M, Yeh C, Korneluk RG and Chow T. (2000) Translational upregulation of $\mathrm{X}$-linked inhibitor of apoptosis (XIAP) increases resistance to radiation induced cell death. Oncogene 19: 4174-4177

22. Harigai M, Miyashita T, Hanada M and Reed JC. (1996) A cis-acting element in the BCL-2 gene controls expression through translational mechanisms. Oncogene 12: 1369-1374

23. MacGregor GR, Nolan GP, Fiering S, Roederer M and Herzenberg LA. (1991) Use of $E$. coli lacZ ( $\beta$-galactosidase) as a reporter gene. In Methods in Molecular Biology, Murray EJ, Walker JM, eds (Clifton, NJ: Humana Press Inc.) pp. 217-235 